\title{
Proteins of the VEGFR and EGFR pathway as predictive markers for adjuvant treatment in patients with stage II/III colorectal cancer: results of the FOGT-4 trial
}

Thomas Thomaidis ${ }^{1}$, Annett Maderer ${ }^{1}$, Andrea Formentini ${ }^{2}$, Susanne Bauer ${ }^{1}$, Mario Trautmann ${ }^{1}$, Michael Schwarz ${ }^{1}$, Wiebke Neumann ${ }^{1}$, Jens Martin Kittner ${ }^{1}$, Arno Schad ${ }^{3}$, Karl-Heinrich Link', Johannes Wilhelm Rey ${ }^{5}$, Arndt Weinmann ${ }^{1}$, Arthur Hoffman ${ }^{5}$, Peter Robert Galle ${ }^{1}$, Marko Kornmann ${ }^{2^{*}}$ and Markus Moehler ${ }^{1^{*}}$

\begin{abstract}
Background: Unlike metastatic colorectal cancer (CRC) there are to date few reports concerning the predictive value of molecular biomarkers on the clinical outcome in stage II/III CRC patients receiving adjuvant chemotherapy. Aim of this study was to assess the predictive value of proteins related with the EGFR- and VEGFR- signalling cascades in these patients.

Methods: The patients' data examined in this study were from the collective of the 5-FU/FA versus 5-FU/FA/irinotecan phase III FOGT-4 trial. Tumor tissues were stained by immunohistochemistry for VEGF-C, VEGF-D, VEGFR-3, Hif-1 a, PTEN, AREG and EREG expression and evaluated by two independent, blinded investigators.

Survival analyses were calculated for all patients receiving adjuvant chemotherapy in relation to expression of all makers above.
\end{abstract}

Results: Patients with negative AREG and EREG expression on their tumor had a significant longer DFS in comparison to AREG/EREG positive ones $(p<0.05)$. The benefit on DFS in AREG-/EREG- patients was even stronger in the group that received 5-FU/FA/irinotecan as adjuvant treatment ( $p=0.002$ ). Patients with strong expression of PTEN profited more in terms of OS under adjuvant treatment containing irinotecan $(p<0.05)$. Regarding markers of the VEGFR- pathway we found no correlation of VEGF-C- and VEGFR-3 expression with clinical outcome. Patients with negative VEGF-D expression had a trend to live longer when treated with 5-FU/FA ( $p=0.106)$. Patients who were negative for Hif- 1 $a$, were disease-free in more than $50 \%$ at the end of the study and showed significant longer DFS-rates than those positive for Hif-1 a ( $p=0.007)$. This benefit was even stronger at the group treated with 5-FU/FA/irinotecan ( $p=0.026)$. Finally, AREG-/EREG-/PTEN+ patients showed a trend to live longer under combined treatment combination.

Conclusions: The addition of irinotecan to adjuvant treatment with 5-FU/FA does not provide OS or DFS benefit in patients with stage II/III CRC. Nevertheless, AREG/EREG negative, PTEN positive and Hif-1 a negative patients might profit significantly in terms of DFS from a treatment containing fluoropyrimidines and irinotecan. Our results suggest a predictive value of these biomarkers concerning adjuvant chemotherapy with 5-FU/FA +/- irinotecan in stage II/III colorectal cancer.

Keywords: Stage II/III colorectal cancer, Predictive biomarkers, EGFR, VEGFR, Amphiregulin, Epiregulin, PTEN, Hif-1 alpha, Adjuvant chemotherapy

\footnotetext{
* Correspondence: Marko.Kornmann@uniklinik-ulm.de; moehler@mail.uni-mainz.de

${ }^{2}$ Department of Surgery, University Hospital, Ulm, Germany

'I. Medical Department, Johannes-Gutenberg University, Mainz, Germany

Full list of author information is available at the end of the article
} 


\section{Introduction}

Colorectal cancer (CRC) is the third most common malignancy and one of the most common causes of cancerrelated death in the western world [1]. The progress that has been made over the past decades in the field of systemic therapy, radiological imaging and surgical interventions resulted in a significant improvement of overall survival (OS) rates especially in patients with distant metastasis [2]. Currently, the 2-year estimated OS rates in patients with metastatic disease reach $22 \%$ [2], whereas patients with local advanced colorectal cancer following adjuvant chemotherapy show a 5-year disease free survival (DFS) in 73.3\% [3]. The development of new therapeutic strategies associated with improved OS and DFS rates in patients with CRC is still the focus of clinical research, but requires a detailed understanding of the biological processes that regulate the establishment and progression of malignant tumors.

One of the main difficulties to establish efficient therapies for human cancer is the great heterogeneity of the disease. Although many genetic and epigenetic alterations have been identified in cancer cells, the elucidation of their role as potential therapeutic targets remains a great challenge. In CRC two developmental pathways represent currently therapeutic objectives in clinical practice: the vascular endothelial growth factor receptor- (VEGFR-) and the epidermal growth factor receptor- (EGFR-) pathway.

VEGF-C and VEGF-D are ligands to VEGFR-2 and VEGFR-3 [4] and are associated with tumor growth and metastasis in multiple cancers [5-7]. In CRC the activation of the VEGFR-3 mediated cascade leads, in crosstalk with other intracellular pathways [8-10], to angiogenesis and mainly to lymphangiogenesis and therefore is involved in lymphatic metastasis [11-13]. In hypoxia, survival is associated with the formation of blood vessels and is being promoted via activation of VEGF. In such conditions the transcription factor hypoxia-inducible factor (Hif-1) $\alpha$ activates a large number of genes including VEGF via binding in its regulatory region [14]. Its role in promoting angiogenesis and invasion has been shown in multiple cancers [15-18], whereas recent studies have provided evidence of Hif- $1 \alpha$ mediated resistance to radiochemotherapy, suggesting Hif-1 $\alpha$ as a putative therapeutic target $[19,20]$.

On the other hand, the stimulation of EGFR results, through the activation of a complex network of pathways, including the MAPK kinase cascade and P13K/ ATK pathway, in an increased cellular proliferation, angiogenesis and loss of apoptosis [21,22]. Amphiregulin (AREG) and epiregulin (EREG) are, among others, ligands of EGFR and activate the EGFR mediated intracellular cascade [23]. Increased concentrations of both proteins have been found in various cancers including CRC [24-26], whereas their potential therapeutic use has been suggested in vitro and in vivo $[27,28]$. Similarly, the tumor suppressor gene PTEN regulates negatively the P13K/ATK pathway acting as a downstream effector of EGFR [29]. Inactivation or loss of PTEN protein expression is found in up to $30 \%$ of sporadic CRC [30,31] and is likely to be associated with resistance to anti-EGFR monoclonal antibodies in KRASwt patients [32].

In light of the high-degree of complexity and crosstalk of the biological systems it is important to identify the predictive factors for clinical outcomes to achieve treatment optimization. In contrast to metastatic CRC, there are to date no comparative studies that focus on a correlation of VEGFR and EGFR related pathways with the clinical outcome in patients with local advanced colon cancer. The aim of this study was therefore to examine and compare the effect of combined adjuvant chemotherapy with 5-FU/FA (folinic acid) versus the combination of 5-FU/FA and irinotecan in patients with locally advanced colon cancer in relation to tumor VEGF-C, VEGF-D, VEGFR-3, Hif-1 $\alpha$, EREG, AREG and PTEN expression.

\section{Materials and methods \\ Patients}

The patient data examined in this study $(n=269)$ originate from the collective of the 5-FU/FA/irinotecan vs. 5-FU/FA trial of the German 'Research Group Oncology of Gastrointestinal Tumors' (FOGT-4). Aim of the study was to investigate the efficacy and safety of adding irinotecan to 5-FU/FA to patients with locally advanced colon cancer in adjuvant setting. Primary end point was OS, and secondary end points were recurrence-free survival, toxicity, quality of life and determination of predictive and prognostic makers for treatment. Eligibility criteria were the R0-resection of a locally advanced adenocarcinoma of the colon in pathological UICC stage III (pTxpNposM0R0) or IIB (pT4pN0M0R0). Patients had to be over 18 years old and gave written informed consent according to the Helsinki protocol before entering the study, which was approved by the ethics committees of the participating institutions (Ref. Nr: \#727/ 2001). The study was approved by the Ethics Committee of the University of Ulm.

\section{Treatment}

The participants were randomized into two treatment arms. The 5-FU/FA/irinotecan group received infusional irinotecan $80 \mathrm{mg} / \mathrm{m}^{2}$ over 60 minutes and FA $500 \mathrm{mg} / \mathrm{m}^{2}$ over 2 hours, followed by an infusion of 5-FU $2000 \mathrm{mg} / \mathrm{m}^{2}$ over 24 hours as previously described [33]. Patients in the 5-FU/FA therapy arm received FA $200 \mathrm{mg} / \mathrm{m}^{2}$ as short intravenously (i.v) infusion combined with the i.v. administration of 5 -FU $2000 \mathrm{mg} / \mathrm{m}^{2}$ over 2 hours as described 
before $[33,34]$. The duration of the adjuvant chemotherapy was ca. 6 months.

\section{Immunohistochemistry}

The expression of AREG, EREG, VEGF-C, VEGF-D, VEGFR-3, PTEN and Hif- $1 \alpha$ was analyzed by immunohistochemistry (IHC). Paraffin-embedded tissue samples were obtained from 185 patients for AREG, 183 for EREG, 204 for VEGF-C, 203 for VEGF-D, 202 for VEGFR-3, 115 for Hif- $1 \alpha$ and 122 for PTEN due to limited availability of material (Additional file 1, Table 1).

Three $\mu \mathrm{m}$ thick tissue sections were cut and mounted on super frost slides. These were deparaffinized, rehydrated and peroxidase blocked $\left(3 \% \mathrm{H}_{2} \mathrm{O}_{2}\right.$ in methanol, $30 \mathrm{~min}$ ). After blocking of nonspecific protein binding sites by using different strategies (Table 2), slides were incubated with the respective primary antibodies AREG and EREG (AF262 and AF1195, both R\&D Systems), VEGF-C, VEGF-D, VEGFR-3 and Hif- $1 \alpha$ (sc-9047, sc13085, sc 321, sc-53546, all Santa Cruz Biotechnology,) and PTEN (9188 s, Cell Signaling; more details in Table 2). After incubation with secondary antibody the specific

Table 1 Marker expression on tumor tissues in patients with stage II/III CRC treated with 5-FU/FA vs 5-FU/FA/irinotecan

\begin{tabular}{|c|c|c|c|}
\hline & $\begin{array}{l}\text { Total study } \\
\text { population }\end{array}$ & 5-FU/FA/irinotecan & 5-FU/FA \\
\hline & $n=269$ & $n=136(50.6 \%)$ & $n=133(49.4 \%)$ \\
\hline AREG & 185 & 94 & 91 \\
\hline negative & $164(88.6 \%)$ & $84(89.4 \%)$ & 80 (87.9\%) \\
\hline positive & $21(11.4 \%)$ & 10 (10.6\%) & 11 (12.1\%) \\
\hline EREG & 183 & 90 & 93 \\
\hline negative & 143 (78.1\%) & 69 (76.7\%) & 74 (79.6\%) \\
\hline positive & 40 (21.9\%) & $21(23.3 \%)$ & 19 (20.4\%) \\
\hline VEGF-C & 204 & 106 & 98 \\
\hline negative & $91(44.6 \%)$ & 51 (48.1\%) & 40 (40.8\%) \\
\hline positive & 113 (55.4\%) & 55 (51.9\%) & $58(59.2 \%)$ \\
\hline VEGF-D & 203 & 106 & 97 \\
\hline negative & $61(30 \%)$ & 35 (33\%) & $26(26.8 \%)$ \\
\hline positive & $142(70 \%)$ & $71(77 \%)$ & $71(73.2 \%)$ \\
\hline VEGFR-3 & 202 & 103 & 99 \\
\hline negative & $115(56.9 \%)$ & $57(55.3 \%)$ & $58(58.6 \%)$ \\
\hline positive & 87 (43.1\%) & 46 (44.7\%) & 41 (41.4\%) \\
\hline Hif-1 alpha & 115 & 62 & 53 \\
\hline negative & $91(79.1 \%)$ & $49(79 \%)$ & $42(79.2 \%)$ \\
\hline positive & $24(20.9 \%)$ & $13(21 \%)$ & $11(20.8 \%)$ \\
\hline PTEN & 122 & 64 & 58 \\
\hline negative & $74(60.7 \%)$ & $38(59.4 \%)$ & $36(62.1 \%)$ \\
\hline positive & 48 (39.3\%) & $26(40.6 \%)$ & 22 (37.9\%) \\
\hline
\end{tabular}

antibody binding was visualized using DAB solution (Dako, Germany). The tissues were counterstained by hemalaun solution (Dako, Germany). Between each step of staining the specimens were washed in DPBS.

Evaluation of staining was performed by two independent, blinded investigators.

\section{Statistical analysis}

The staining was evaluated semiquantitatively per intensity and the extent of the stained tumor area. A cut-off of $25 \%$ stained tumor cells were considered as positive staining for the markers. The survival analysis was performed by using the Kaplan-Meier method and the log rank test. To investigate the association between the results of immunohistochemistry obtained for all markers and clinical-pathological parameters, univariate statistical analysis were performed using Pearson's Chi- 2 test or Fisher's exact test.

\section{Results}

Immunohistochemical analysis in respect to groups of treatment

As seen in Table 1 the number of tissue samples that were stained for all markers varied between 122 -for PTEN- and 204 -for VEGF-C. Nevertheless, there was an equal distribution of the patients in regards of treatment and positivity of markers. In the statistical analysis of EGFR pathway $11.4 \%, 21.9 \%$ and $39.3 \%$ of the samples were found positive for AREG-, EREG- and PTEN- expression respectively. Regarding the VEGFR pathway $55.4 \%, 70 \%$ and $43.1 \%$ of the specimens showed positivity for VEGF-C, VEGF-D and VEGFR-3. The analysis of Hif-1 $\alpha$ included a total of 115 tissue samples. A positive staining for Hif- $1 \alpha$ was observed in 24 cases (20.9\%). In Figure 1 examples of positive and negative immunohistochemical staining are shown for each marker.

\section{General statistical analysis}

In terms of efficacy, we detected no difference regarding DFS and OS after the addition of irinotecan to 5-FU/FA. Furthermore, there was no correlation between age, UICC stage, $\mathrm{T}-, \mathrm{N}$ - stage and expression of the tested markers (data not shown).

\section{Results for the EGFR- pathway}

We found no statistically significant difference in respect to the expression status of AREG or EREG and the survival of the patients in the total study population. However, patients with negative AREG and EREG expression had a significant longer DFS in comparison to AREG and EREG positive ones independent of the adjuvant treatment (Figure 2A, $\mathrm{p}<0.05$ ). The $\mathrm{OS}$ though, did not differ significantly (Figure 2B). Patients with a negative 
Table 2 Methods for the detection of immunohistochemical expression of the tested markers

\begin{tabular}{|c|c|c|c|c|c|}
\hline & \multirow[t]{2}{*}{ Company } & \multirow{2}{*}{$\begin{array}{l}\text { Antigen } \\
\text { retrieval }\end{array}$} & \multirow{2}{*}{$\begin{array}{l}\text { Blocking } \\
30 \text { 'RT }\end{array}$} & \multirow[t]{2}{*}{$1 . \mathrm{AK}$} & \multirow[t]{2}{*}{ 2.AK } \\
\hline & & & & & \\
\hline \multirow[t]{2}{*}{ AREG } & R\&D Systems & $0,1 \mathrm{M}$ & $5 \%$ swine & 1:75, & LSAB + System-HRP \\
\hline & AF262 & EDTA buffer pH8 & serum & over night & K 0690 \\
\hline \multirow[t]{2}{*}{ EREG } & R\&D Systems & - & $5 \%$ swine & $1: 100$ & LSAB + System-HRP \\
\hline & AF1195 & & serum & over night & K 0690 \\
\hline \multirow[t]{2}{*}{ VEGF-C } & Sant Cruz & - & FFP & $1: 50$ & $\begin{array}{l}\text { Dako Real }{ }^{\mathrm{TM}} \text { EnVision }{ }^{\mathrm{TM}} \text { Detection } \\
\text { System }\end{array}$ \\
\hline & sc-9047 & & & over night & K 5007 \\
\hline \multirow[t]{2}{*}{ VEGF-D } & Sant Cruz & $0.01 \mathrm{M}$ & FFP & $1: 50$ & $\begin{array}{l}\text { Dako Real }{ }^{\mathrm{TM}} \text { EnVision }{ }^{\mathrm{TM}} \text { Detection } \\
\text { System }\end{array}$ \\
\hline & sc-13085 & Citrat buffer & & $2 \mathrm{~h} \mathrm{RT}$ & K 5007 \\
\hline \multirow[t]{2}{*}{ VEGFR-3 } & Sant Cruz & $0.01 \mathrm{M}$ & FFP & 1:100 & LSAB + System-HRP \\
\hline & sc-321 & Citrat buffer & & $2 \mathrm{~h} \mathrm{RT}$ & K 0690 \\
\hline \multirow[t]{2}{*}{ Hif-1 a } & Sant Cruz & $0,1 \mathrm{M}$ & $5 \%$ swine & $1: 50$ & LSAB + System-HRP \\
\hline & sc-53546 & EDTA buffer pH8 & serum & over night & K 0690 \\
\hline \multirow[t]{2}{*}{ PTEN } & Cell Signaling & $0.01 \mathrm{M}$ & $5 \%$ goat & $1: 75$ & $\begin{array}{l}\text { Dako Real }{ }^{\mathrm{TM}}{ }^{\mathrm{E} n V i s i o n}{ }^{\mathrm{TM}} \text { Detection } \\
\text { System }\end{array}$ \\
\hline & $9188 \mathrm{~s}$ & Citrat buffer & serum & over night & K 5007 \\
\hline
\end{tabular}

AREG- or EREG- state showed a trend for a longer DFS over a period of about 7 years under the combined combination of 5-FU/FA/irinotecan (Figures $3 \mathrm{~A}$ and 3B). Patients with a negative state for AREG and EREG benefited strongly from the addition of irinotecan in the adjuvant backbone treatment, in terms of DFS over 80 months (Figure $3 \mathrm{C}, \mathrm{p}=0.002$ ). The median DFS for AREG- and EREG- positive patients was 45 months under 5-FU/FA/irinotecan, whereas more than half of the patients with negative immunohistochemistry for AREG and EREG were disease free at the end of the study. Furthermore, PTEN expression appeared to have no significant impact on the survival rates of the total study population (Figure 4A). However, in the group of 5-FU/FA/irinotecan patients positive for PTEN benefited in terms of OS compared to PTEN- negative ones $(\mathrm{p}<0.05$, Figure $4 \mathrm{~B})$.

\section{Results for the VEGFR- pathway}

The expression of VEGF-D, VEGF-C and VEGFR-3 in tumor tissues did not show a direct impact on survival in the total study population. In the 7-year survival, a

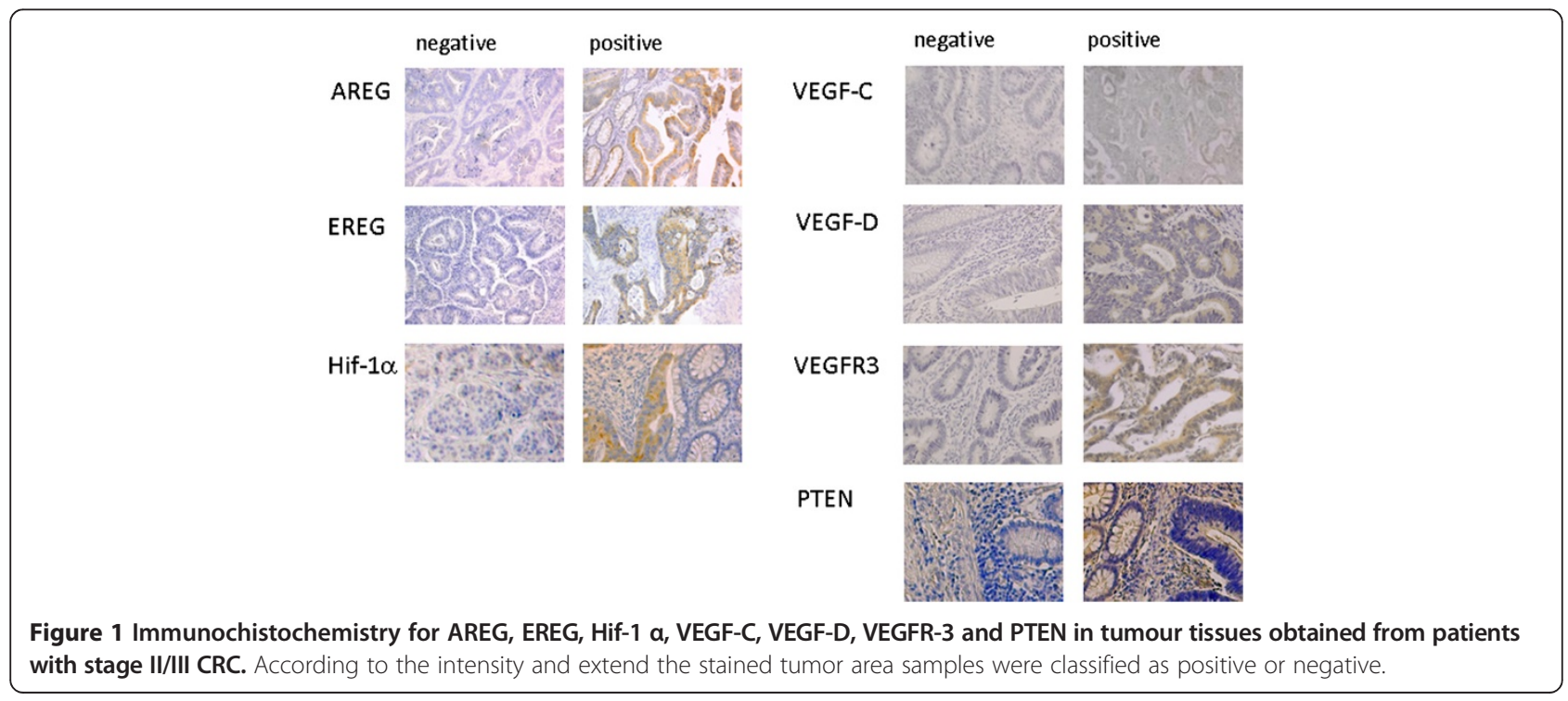



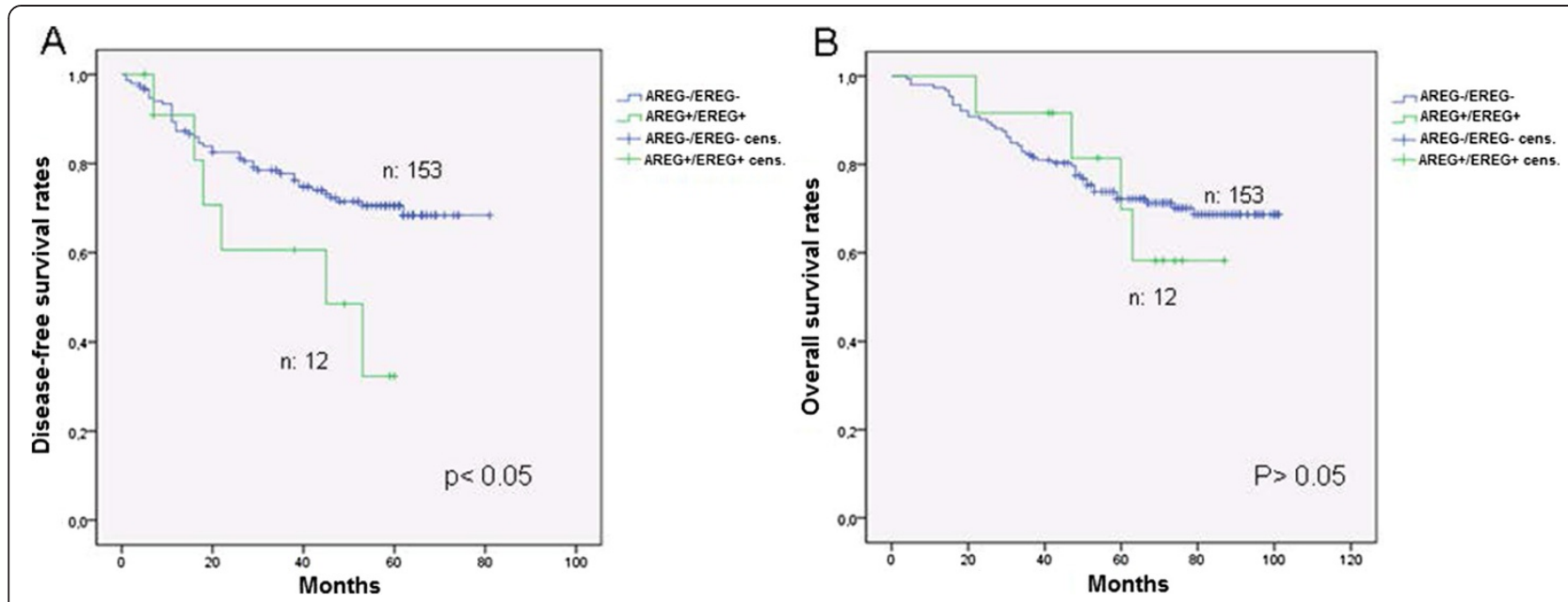

Figure 2 Survival analysis in patients receiving adjuvant treatment in relation to AREG- and EREG- expression. A. Disease-free survival rates. B. overall survival rates.

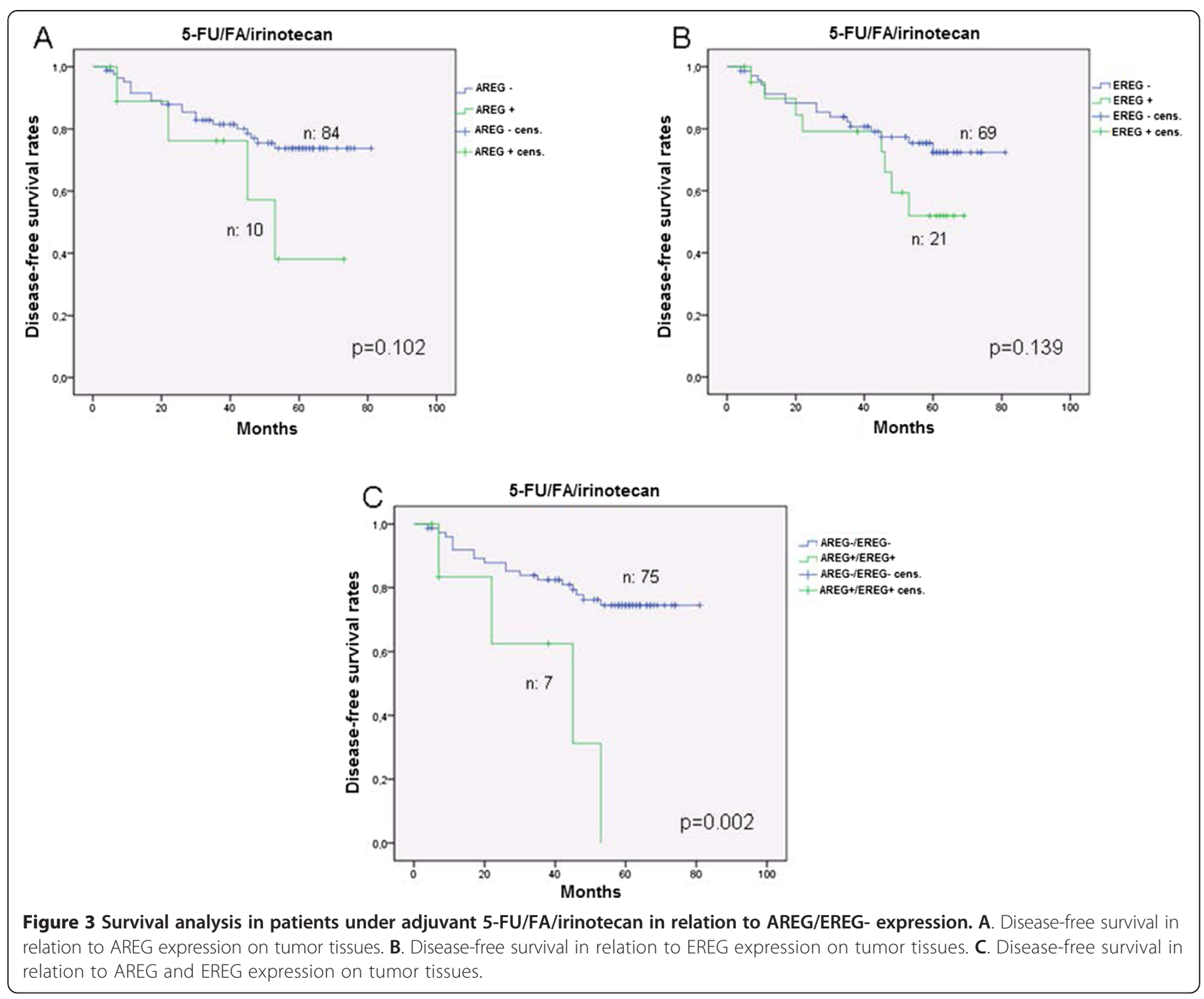



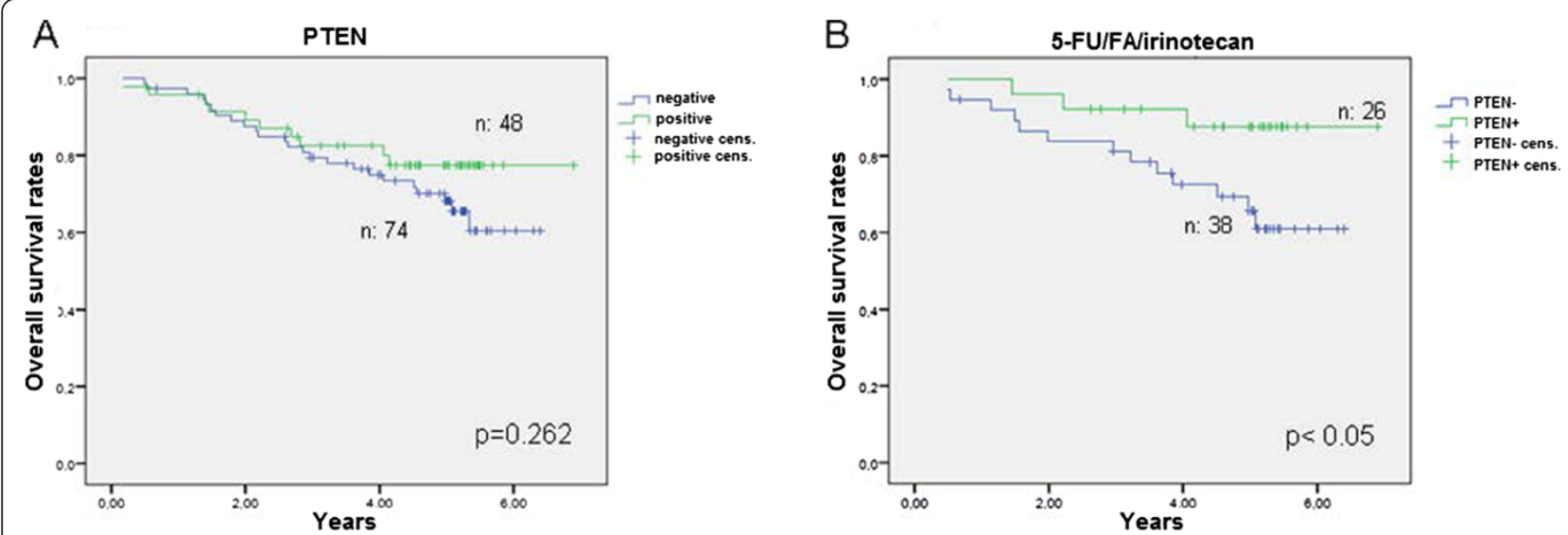

Figure 4 Overall survival analysis for patients according to tumor PTEN-status. A. in the whole population B. in the subgroup treated with adjuvant 5-FU/FA/irinotecan.

trend for a longer DFS was found for patients with no VEGF-D expression ( $\mathrm{p}=0.155$, Figure $5 \mathrm{~A})$. While VEGF$\mathrm{D}$ negative patients showed a trend to remain disease free towards treatment with 5-FU/FA $(p=0.106$, Figure $5 B)$, no benefit in survival was observed under the combined adjuvant treatment (Figure 5C).

In respect to Hif- $1 \alpha$, the median DFS of patients with positive status was 3.3 years for the entire group, 2.1 years for the 5-FU/FA group and 3.9 years for the 5 -FU/FA/irinotecan group. Patients who were negative for Hif- $1 \alpha$, were in more than $50 \%$ disease-free at the end of the examination period in all above cases $(\mathrm{p}=0.007$, $p=0.059$ and $p=0.026$ respectively, Figure 6 ).

\section{Combining results for both pathways}

Patients who had a negative expression for AREG, EREG, Hif- $1 \alpha$ and positive for PTEN represented 9\% of the total study population and showed not significant prolonged OS and DFS under 5-FU/FA/irinotecan treatment (Figure 7A). 34 patients were AREG-/EREG-/PTEN + and had a trend to live longer under the triple combination $(\mathrm{p}=0.071$, Figure 7B).

\section{Discussion}

There is an increasing number of reports concerning the role of biomarkers on the identification of those patients who will benefit from treatment with targeted agents [35-38]. In this study we evaluated the impact of the tyrosine kinase receptor ligands VEGF-C, -D, AREG, EREG, as well as Hif- $1 \alpha$, PTEN and of the VEGFR-3 on disease recurrence and survival in patients with CRC receiving adjuvant chemotherapy. This is -to our knowledgethe first study analyzing all these parameters in the specific target population of CRC stage II/III.

Indeed, unlike metastatic $\mathrm{CRC}$, there have been only a limited number of trials that attempted to determine prognostic and predictive biomarkers in resected CRC. Current evidence suggests that the presence of high microsatellite instability (MSI-h) in tumor tissues is associated with a longer DFS and OS in non-metastatic CRC [33,39-41]. The ongoing B-CAST trial [42] evaluates the protein expression of thymidine phosphorylase (TP), dihydropyrimidine dehydrogenase (DPD), EGFR and VEGF in 2128 patients with stage III CRC, but the results are yet to be published. Other studies proposed loss of SMAD4 [43], high expression of wt-p53 [44], NF-kB negativity or JNK positivity [45] as possible biomarkers associated with longer time to relapse in stage II/III CRC. Nevertheless, there has been so far no sufficient validation of their use in clinical practice.

Similarly to the findings of Tikidzhieva et al. [33] we observed in our analysis no benefit of the addition of irinotecan to adjuvant 5-FU/FA in terms of DFS and OS (data not shown). These results are consistent with those of previously published phase III trials [46-48]. Nevertheless, we cannot exclude the possibility that irinotecan might be effective for subgroups of patients with stage II/III CRC whose tumors present specific molecular patterns.

As depicted in Table 1 the tumor tissues in our study showed higher levels of VEGF-C, VEGF-D, VEGFR-3 expression when compared to proteins related to the EGFR pathway. Nevertheless, these expression levels should not be considered representative since they may vary among tumors with different entity and TNM stage. It is characteristic, that the immunohistochemical detection of VEGF-C and VEGF-D in stage II/III colorectal adenocarcinoma varies between $43 \%-77 \%$ and 50\%-64\% [49,50] respectively.

In our study we demonstrated a statistical significant benefit in terms of DFS for patients who lacked AREG 


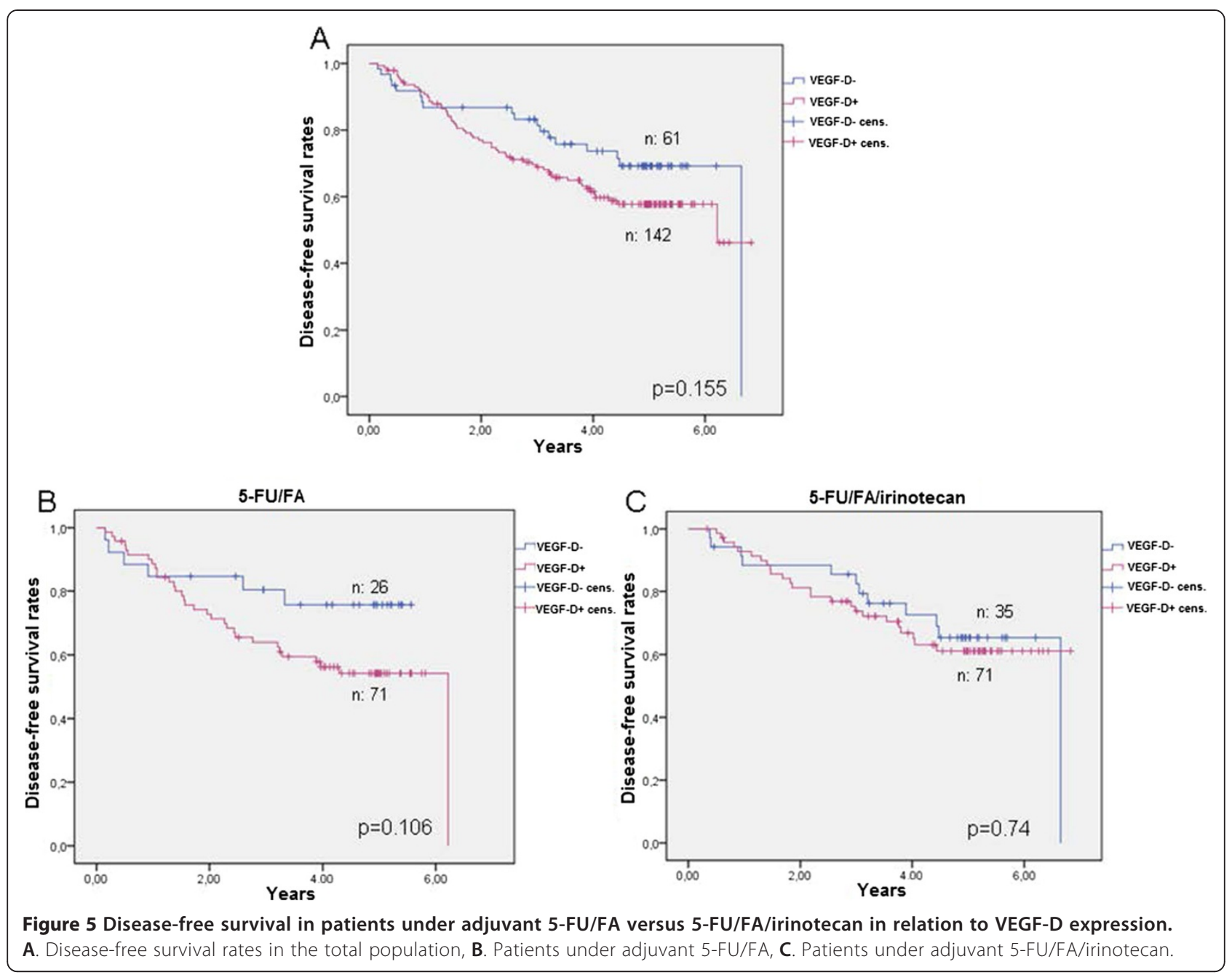

and EREG expression. This benefit was even stronger when AREG-/EREG- patients received adjuvant therapy including irinotecan (Figure 3). Our findings are consistent with those of Jacobs et al. who postulated that expression of AREG/EREG can predict the outcome for KRAS wt stage IV CRC when treated with cetuximab and irinotecan [51]. In this study a positive prognosis associated with AREG/EREG expression for EGFR targeted treatment was shown. This discrepancy in comparison to our results might be attributed to the applied treatment with anti-EGFR agents or to the metastasized stage of the examined patients in Jacobs' study. Indeed, EGFR blockage for stage II/III CRC patients under adjuvant treatment has not been proven beneficial so far [52]. Furthermore, the RAS-status was not tested in our study since the limited number of samples in the tested subgroups might lead to false interpretations.

Emerging data from in vitro studies with gastric [53] and colorectal [54] cancer cell lines demonstrated a synergistic effect of EGFR-inhibitors and irinotecan. Yashiro et al. showed that EGFR-inhibition could enhance the activity of SN-38, an active metabolite of irinotecan, in SN-38 resistant gastric cancer cell lines [53]. They proposed a down-regulation of $\mathrm{SN}-38$ metabolism related genes through EGFR-inhibition, which might also explain the longer DFS of AREG and EREG negative patients under irinotecan treatment in our study.

Enhancement of SN-38 efficacy has also been demonstrated in ovarian cancer cells that had high PTEN expression [55]. Herein the proposed mechanism was a synergistic inhibition of topoisomerase-I activity. In deed, in our study PTEN + patients treated with 5-FU/FA/irinotecan had significant longer OS than PTEN- patients, which has also been shown from our group in advanced gastric cancer before [56].

In the last part of our study we examined whether proteins of the VEGFR- pathway could play a predictive role to adjuvant chemotherapy in patients with CRC UICC II and III. We noticed a trend for a longer DFS in VEGF-D 

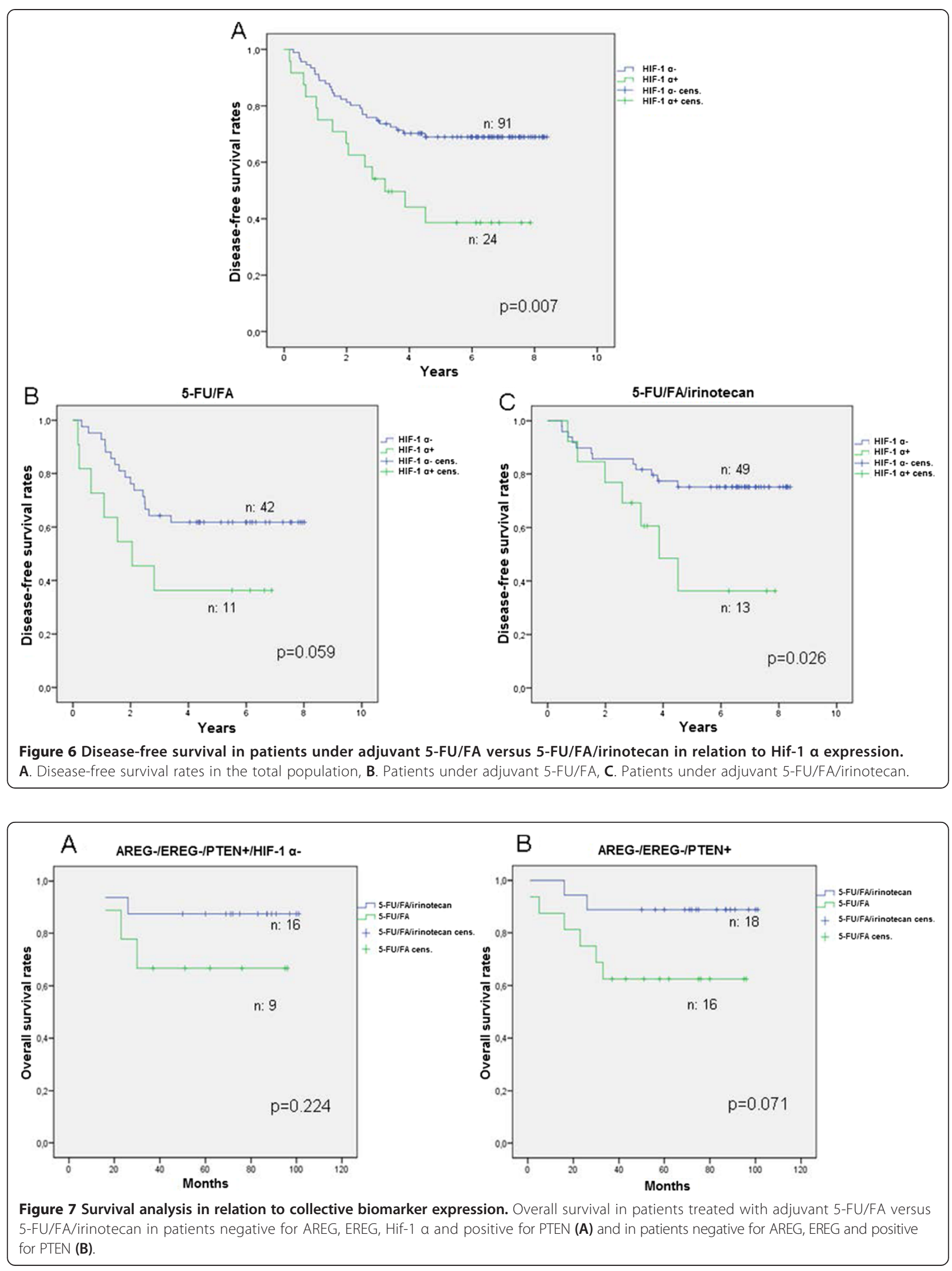
negative patients under the treatment with 5-FU/FA (Figure 5B). A further relation of VEGF-C or VEGF-R3 with the survival of patients was not observed. These results are consistent with the findings of the AVANT and NSABP C08 trials published previously $[57,58]$. Both of these trials reported no benefit from the addition of bevacizumab to the combination of fluoropyrimidines and oxaliplatin in the adjuvant treatment of stage II/III CRC. Regarding Hif-1 $\alpha$ expression on tumor tissues we demonstrated a statistically significant prolonged DFS for patients with negative Hif- $1 \alpha$ expression, especially for those under irinotecan treatment. In agreement with previous in vitro and in vivo models [59] we showed that the anti-tumor efficacy of irinotecan is stronger when Hif- $1 \alpha$ on tumor tissues is down regulated. Since irinotecan inhibits the accumulation of Hif-1 $\alpha[60,61]$, our findings suggest a further mechanism of interaction between cytotoxicity of irinotecan and Hif- $1 \alpha$.

In the subgroup of AREG-/EREG-/Hif- $1 \alpha$-/PTEN + patients we found a non statistically significant survival benefit under the combined treatment combination. The lack of significance could be attributed to the small number of patients with the specific biomarker combination. However, AREG-/EREG-/PTEN + patients showed a clear trend to profit from the addition of irinotean to the adjuvant regime (Figure 7).

\section{Conclusions}

There is an increasing interest in personalized therapy for colon cancer patients receiving adjuvant therapy. This is -to our knowledge- the first study investigating the role of multiple biomarkers of the EGFR- and VEGFRpathway on the treatment outcome in patients with stage II/III CRC. We showed that an adjuvant therapy containing irinotecan might be beneficial for AREG/EREG negative, PTEN positive and Hif- $1 \alpha$ negative patients. However, the decision of the adjuvant regime should be always based upon the clinical characteristics of the patients including age, pre-existing treatment and side effects (i.e. oxaliplatin induced neuropathy). Nevertheless, further prospective studies including a large number of patients with stage II/III CRC are necessary in order to evaluate which molecular patterns might serve as predictive markers for treatment outcome in these patients.

\section{Additional file}

Additional file 1: Consort Diagram of the study process.

\section{Abbreviations}

VEGFR-3: Vascular endothelial growth factor receptor 3; EGFR: Epidermal growth factor receptor; VEGF: Vascular endothelial growth factor;
AREG: Amphiregulin; EREG: Epiregulin; Hif-1 a: Hypoxia-inducible factor 1 alpha; FOGT: Research group oncology of gastrointestinal tumors; OS: Overall survival; DFS: Disease free survival; CRC: Colorectal cancer; FA: Folinic acid; IHC: Immunohistochemistry; MSI-h: High microsatellite instability; TP: Thymidine phosphorylase; DPD: Dihydropyrimidine dehydrogenase.

\section{Competing interests}

The authors declare that they have no competing interests.

\section{Authors' contributions}

TT: acquisition of data, analysis and interpretation of data, drafting of the manuscript, critical revision of the manuscript, AM: acquisition of data, analysis and interpretation of data, critical revision of the manuscript, statistical analysis. AF: study concept and design, patients' recruitment, SB, MT, MS, WN: acquisition of data, analysis and interpretation of data. JMK: patient's recruitment, statistical analysis, AS: acquisition of data, K-HL: patient's recruitment, critical revision of the manuscript, technical or material support, JWR, AW, AH: patient's recruitment, technical or material support, statistical analysis, PRG: critical revision of the manuscript, administrative support, study supervision, MK, MM: study concept and design, drafting of the manuscript, critical revision of the manuscript, study supervision. All the authors critically reviewed the paper. All authors read and approved the final manuscript.

\section{Acknowledgments}

The authors would like to thank the investigators and patients who participated in this trial. Special thanks go Wiebke Neumann for her excellent laboratory work. The $\mathrm{IHC}$ results of the manuscript are part of the MD theses of M. Schwarz, S. Bauer and M. Trautmann.

\section{Author details}

'I. Medical Department, Johannes-Gutenberg University, Mainz, Germany. ${ }^{2}$ Department of Surgery, University Hospital, Ulm, Germany. ${ }^{3}$ Department of Pathology, Johannes-Gutenberg University, Mainz, Germany. ${ }^{4}$ Department of Surgery, Asklepios Clinic, Wiesbaden, Germany. ${ }^{5}$ Medical Department, Marienhospital, Frankfurt, Germany.

Received: 8 July 2014 Accepted: 24 September 2014

Published online: 02 October 2014

\section{References}

1. Siegel R, Naishadham D, Jemal A: Cancer statistics, 2012. CA Cancer J Clin 2012, 62(1):10-29.

2. Golan T, Urban D, Berger R, Lawrence YR: Changing prognosis of metastatic colorectal adenocarcinoma: Differential improvement by age and tumor location. Cancer 2013, 119(16):3084-3091.

3. Andre T, Boni C, Navarro M, Tabernero J, Hickish T, Topham C, Bonetti A, Clingan P, Bridgewater J, Rivera F, de Gramont A: Improved overall survival with oxaliplatin, fluorouracil, and leucovorin as adjuvant treatment in stage II or III colon cancer in the MOSAIC trial. J Clin Oncol 2009, 27(19):3109-3116.

4. Cao Y: Positive and negative modulation of angiogenesis by VEGFR1 ligands. Sci Signal 2009, 2(59):re1.

5. Wu QW, She HQ, Liang J, Huang YF, Yang QM, Yang QL, Zhang ZM: Expression and clinical significance of extracellular matrix protein 1 and vascular endothelial growth factor-C in lymphatic metastasis of human breast cancer. BMC Cancer 2012, 12:47.

6. Wang TB, Chen ZG, Wei XQ, Wei B, Dong WG: Serum vascular endothelial growth factor- $C$ and lymphoangiogenesis are associated with the lymph node metastasis and prognosis of patients with colorectal cancer. ANZ J Surg 2011, 81(10):694-699.

7. Kawakami M, Furuhata T, Kimura Y, Yamaguchi K, Hata F, Sasaki K, Hirata K: Expression analysis of vascular endothelial growth factors and their relationships to lymph node metastasis in human colorectal cancer. J Exp Clin Cancer Res 2003, 22(2):229-237.

8. Tammela T, Zarkada G, Nurmi H, Jakobsson L, Heinolainen K, Tvorogov D, Zheng W, Franco CA, Murtomaki A, Aranda E, Miura N, Yla-Herttuala S, Fruttiger M, Makinen T, Eichmann A, Pollard JW, Gerhardt H, Alitalo K: VEGFR-3 controls tip to stalk conversion at vessel fusion sites by reinforcing Notch signalling. Nat Cell Biol 2011, 13(10):1202-1213. 
9. Zheng W, Tammela T, Yamamoto M, Anisimov A, Holopainen T, Kaijalainen S, Karpanen T, Lehti K, Yla-Herttuala S, Alitalo K: Notch restricts lymphatic vessel sprouting induced by vascular endothelial growth factor. Blood 2011, 118(4):1154-1162.

10. Weis $S M$, Cheresh DA: alphaV integrins in angiogenesis and cancer. Cold Spring Harb Perspect Med 2011, 1(1):a006478.

11. Hanrahan V, Currie MJ, Gunningham SP, Morrin HR, Scott PA, Robinson BA, Fox SB: The angiogenic switch for vascular endothelial growth factor (VEGF)-A, VEGF-B, VEGF-C, and VEGF-D in the adenoma-carcinoma sequence during colorectal cancer progression. J Pathol 2003, 200(2):183-194

12. Mandriota SJ, Jussila L, Jeltsch M, Compagni A, Baetens D, Prevo R, Banerji S, Huarte J, Montesano R, Jackson DG, Orci L, Alitalo K, Christofori G, Pepper MS: Vascular endothelial growth factor-C-mediated lymphangiogenesis promotes tumour metastasis. EMBO J 2001 20(4):672-682.

13. Karnezis T, Shayan R, Caesar C, Roufail S, Harris NC, Ardipradja K, Zhang YF, Williams SP, Farnsworth RH, Chai MG, Rupasinghe TW, Tull DL, Baldwin ME, Sloan EK, Fox SB, Achen MG, Stacker SA: VEGF-D promotes tumor metastasis by regulating prostaglandins produced by the collecting lymphatic endothelium. Cancer Cell 2012, 21(2):181-195.

14. Forsythe JA, Jiang BH, lyer NV, Agani F, Leung SW, Koos RD, Semenza GL: Activation of vascular endothelial growth factor gene transcription by hypoxia-inducible factor 1. Mol Cell Biol 1996, 16(9):4604-4613.

15. Kuwai T, Kitadai Y, Tanaka S, Onogawa S, Matsutani N, Kaio E, Ito M, Chayama K: Expression of hypoxia-inducible factor-1alpha is associated with tumor vascularization in human colorectal carcinoma. Int J Cancer 2003, 105(2):176-181.

16. Takahashi R, Tanaka S, Hiyama T, Ito M, Kitadai Y, Sumii M, Haruma K, Chayama K: Hypoxia-inducible factor-1alpha expression and angiogenesis in gastrointestinal stromal tumor of the stomach. Oncol Rep 2003, 10(4):797-802.

17. Schindl M, Schoppmann SF, Samonigg H, Hausmaninger $H$, Kwasny W, Gnant M, Jakesz R, Kubista E, Birner P, Oberhuber G: Overexpression of hypoxia-inducible factor 1 alpha is associated with an unfavorable prognosis in lymph node-positive breast cancer. Clin Cancer Res 2002, 8(6):1831-1837.

18. Zhong H, De Marzo AM, Laughner E, Lim M, Hilton DA, Zagzag D, Buechler P, Isaacs WB, Semenza GL, Simons JW: Overexpression of hypoxia-inducible factor 1alpha in common human cancers and their metastases. Cancer Res 1999, 59(22):5830-5835.

19. Unruh A, Ressel A, Mohamed HG, Johnson RS, Nadrowitz R, Richter E, Katschinski DM, Wenger $\mathrm{RH}$ : The hypoxia-inducible factor-1 alpha is a negative factor for tumor therapy. Oncogene 2003, 22(21):3213-3220.

20. Aebersold DM, Burri P, Beer KT, Laissue J, Djonov V, Greiner RH, Semenza GL: Expression of hypoxia-inducible factor-1alpha: a novel predictive and prognostic parameter in the radiotherapy of oropharyngeal cancer. Cancer Res 2001, 61(7):2911-2916.

21. Scaltriti M, Baselga J: The epidermal growth factor receptor pathway: a model for targeted therapy. Clin Cancer Res 2006, 12(18):5268-5272.

22. Ono M, Kuwano M: Molecular mechanisms of epidermal growth factor receptor (EGFR) activation and response to gefitinib and other EGFR-targeting drugs. Clin Cancer Res 2006, 12(24):7242-7251.

23. Harris RC, Chung E, Coffey RJ: EGF receptor ligands. Exp Cell Res 2003, 284(1):2-13

24. Cook PW, Pittelkow MR, Keeble WW, Graves-Deal R, Coffey RJ Jr, Shipley GD: Amphiregulin messenger RNA is elevated in psoriatic epidermis and gastrointestinal carcinomas. Cancer Res 1992, 52(11):3224-3227.

25. Saeki T, Stromberg K, Qi CF, Gullick WJ, Tahara E, Normanno N, Ciardiello F, Kenney N, Johnson GR, Salomon DS: Differential immunohistochemical detection of amphiregulin and cripto in human normal colon and colorectal tumors. Cancer Res 1992, 52(12):3467-3473.

26. Nishimura T, Andoh A, Inatomi O, Shioya M, Yagi Y, Tsujikawa T, Fujiyama Y: Amphiregulin and epiregulin expression in neoplastic and inflammatory lesions in the colon. Oncol Rep 2008, 19(1):105-110.

27. Khambata-Ford S, Garrett CR, Meropol NJ, Basik M, Harbison CT, Wu S, Wong TW, Huang X, Takimoto CH, Godwin AK, Tan BR, Krishnamurthi SS, Burris HA 3rd, Poplin EA, Hidalgo M, Baselga J, Clark EA, Mauro DJ: Expression of epiregulin and amphiregulin and K-ras mutation status predict disease control in metastatic colorectal cancer patients treated with cetuximab. J Clin Oncol 2007, 25(22):3230-3237.
28. McBryan J, Howlin J, Napoletano S, Martin F: Amphiregulin: role in mammary gland development and breast cancer. J Mammary Gland Biol Neoplasia 2008, 13(2):159-169.

29. Salmena L, Carracedo A, Pandolfi PP: Tenets of PTEN tumor suppression. Cell 2008, 133(3):403-414.

30. Naguib A, Cooke JC, Happerfield L, Kerr L, Gay LJ, Luben RN, Ball RY, Mitrou PN, McTaggart A, Arends MJ: Alterations in PTEN and PIK3CA in colorectal cancers in the EPIC Norfolk study: associations with clinicopathological and dietary factors. BMC Cancer 2011, 11:123.

31. Zhou XP, Loukola A, Salovaara R, Nystrom-Lahti M, Peltomaki P, de la Chapelle A Aaltonen LA, Eng C: PTEN mutational spectra, expression levels, and subcellular localization in microsatellite stable and unstable colorectal cancers. Am J Pathol 2002, 161(2):439-447.

32. Frattini M, Saletti $P$, Romagnani $E$, Martin V, Molinari F, Ghisletta M, Camponovo A, Etienne LL, Cavalli F, Mazzucchelli L: PTEN loss of expression predicts cetuximab efficacy in metastatic colorectal cancer patients. Br J Cancer 2007, 97(8):1139-1145.

33. Tikidzhieva A, Benner A, Michel S, Formentini A, Link KH, Dippold W, von Knebel DM, Kornmann M, Kloor M: Microsatellite instability and Beta2-Microglobulin mutations as prognostic markers in colon cancer: results of the FOGT-4 trial. Br J Cancer 2012, 106(6):1239-1245.

34. Link KH, Kornmann M, Staib L, Redenbacher M, Kron M, Beger HG: Increase of survival benefit in advanced resectable colon cancer by extent of adjuvant treatment: results of a randomized trial comparing modulation of 5-FU + levamisole with folinic acid or with interferon-alpha. Ann Surg 2005, 242(2):178-187.

35. Bang YJ, Van Cutsem E, Feyereislova A, Chung HC, Shen L, Sawaki A, Lordick F, Ohtsu A, Omuro Y, Satoh T, Aprile G, Kulikov E, Hill J, Lehle M, Ruschoff J, Kang YK. Trastuzumab in combination with chemotherapy versus chemotherapy alone for treatment of HER2-positive advanced gastric or gastro-oesophageal junction cancer (ToGA): a phase 3, open-label, randomised controlled trial. Lancet 2010, 376(9742):687-697.

36. Laurent-Puig P, Cayre A, Manceau G, Buc E, Bachet JB, Lecomte T, Rougier $P$, Lievre A, Landi B, Boige V, Ducreux M, Ychou M, Bibeau F, Bouche O, Reid J, Stone S, Penault-Llorca F: Analysis of PTEN, BRAF, and EGFR status in determining benefit from cetuximab therapy in wild-type KRAS metastatic colon cancer. J Clin Oncol 2009, 27(35):5924-5930.

37. Bardelli A, Siena S: Molecular mechanisms of resistance to cetuximab and panitumumab in colorectal cancer. J Clin Oncol 2010, 28(7):1254-1261.

38. Meteoglu I, Meydan N, Erkus M: Id-1: regulator of EGFR and VEGF and potential target for colorectal cancer therapy. J Exp Clin Cancer Res 2008, 27:69.

39. Ribic CM, Sargent DJ, Moore MJ, Thibodeau SN, French AJ, Goldberg RM, Hamilton SR, Laurent-Puig P, Gryfe R, Shepherd LE, Tu D, Redston M, Gallinger S: Tumor microsatellite-instability status as a predictor of benefit from fluorouracil-based adjuvant chemotherapy for colon cancer. N Engl J Med 2003, 349(3):247-257.

40. Popat $S$, Hubner $R$, Houlston RS: Systematic review of microsatellite instability and colorectal cancer prognosis. J Clin Oncol 2005, 23(3):609-618

41. Roth AD, Tejpar S, Delorenzi M, Yan P, Fiocca R, Klingbiel D, Dietrich D, Biesmans B, Bodoky G, Barone C, Aranda E, Nordlinger B, Cisar L, Labianca R, Cunningham D, Van Cutsem E, Bosman F: Prognostic role of KRAS and BRAF in stage II and III resected colon cancer: results of the translational study on the PETACC-3, EORTC 40993, SAKK 60-00 trial. J Clin Oncol 2010, 28(3):466-474

42. Ishiguro M, Kotake K, Nishimura G, Tomita N, Ichikawa W, Takahashi K, Watanabe T, Furuhata T, Kondo K, Mori M, Kakeji Y, Kanazawa A, Kobayashi M, Okajima M, Hyodo I, Miyakoda K, Sugihara K: Study protocol of the B-CAST study: a multicenter, prospective cohort study investigating the tumor biomarkers in adjuvant chemotherapy for stage III colon cancer. BMC Cancer 2013, 13:149.

43. Roth AD, Delorenzi M, Tejpar S, Yan P, Klingbiel D, Fiocca R, d'Ario G, Cisar L, Labianca R, Cunningham D, Nordlinger B, Bosman F, Van Cutsem E: Integrated analysis of molecular and clinical prognostic factors in stage II/III colon cancer. J Natl Cancer Inst 2012, 104(21):1635-1646.

44. Huh JW, Kim HR, Kim YJ: Prognostic role of p53 messenger ribonucleic acid expression in patients after curative resection for stage I to III colorectal cancer: association with colon cancer stem cell markers. J Am Coll Surg 2013, 216(6):1063-1069.

45. Ishida K, Nishizuka SS, Chiba T, Ikeda M, Kume K, Endo F, Katagiri H, Matsuo T, Noda H, Iwaya T, Yamada N, Fujiwara H, Takahashi M, Itabashi T, Uesugi N, Maesawa C, Tamura G, Sugai T, Otsuka K, Koeda K, Wakabayashi G: Molecular 
marker identification for relapse prediction in 5-FU-based adjuvant chemotherapy in gastric and colorectal cancers. PLoS One 2012, 7(8):e43236.

46. Sargent $D$, Sobrero A, Grothey A, O'Connell MJ, Buyse M, Andre T, Zheng Y, Green E, Labianca R, O'Callaghan C, Seitz JF, Francini G, Haller D, Yothers G, Goldberg R, de Gramont A: Evidence for cure by adjuvant therapy in colon cancer: observations based on individual patient data from 20,898 patients on 18 randomized trials. J Clin Oncol 2009, 27(6):872-877.

47. Van Cutsem E, Labianca R, Bodoky G, Barone C, Aranda E, Nordlinger B, Topham C, Tabernero J, Andre T, Sobrero AF, Mini E, Greil R, Di Costanzo F, Collette L, Cisar L, Zhang X, Khayat D, Bokemeyer C, Roth AD, Cunningham D: Randomized phase III trial comparing biweekly infusional fluorouracil/ leucovorin alone or with irinotecan in the adjuvant treatment of stage III colon cancer: PETACC-3. J Clin Oncol 2009, 27(19):3117-3125.

48. Ychou M, Hohenberger W, Thezenas S, Navarro M, Maurel J, Bokemeyer C, Shacham-Shmueli E, Rivera F, Kwok-Keung Choi C, Santoro A: A randomized phase III study comparing adjuvant 5 -fluorouracil/folinic acid with FOLFIRI in patients following complete resection of liver metastases from colorectal cancer. Ann Oncol 2009, 20(12):1964-1970.

49. Moehler M, Frings C, Mueller A, Gockel I, Schimanski CC, Biesterfeld S, Galle PR, Holtmann MH: VEGF-D expression correlates with colorectal cancer aggressiveness and is downregulated by cetuximab. World I Gastroenterol 2008, 14(26):4156-4167.

50. George ML, Tutton MG, Janssen F, Arnaout A, Abulafi AM, Eccles SA, Swift RI: VEGF-A, VEGF-C, and VEGF-D in colorectal cancer progression. Neoplasia 2001, 3(5):420-427.

51. Jacobs B, De Roock W, Piessevaux H, Van Oirbeek R, Biesmans B, De Schutter J, Fieuws S, Vandesompele J, Peeters M, Van Laethem JL, Humblet Y, Penault-Llorca F, De Hertogh G, Laurent-Puig P, Van Cutsem E, Tejpar S: Amphiregulin and Epiregulin mRNA Expression in Primary Tumors Predicts Outcome in Metastatic Colorectal Cancer Treated With Cetuximab. J Clin Oncol 2009, 27(30):5068-5074.

52. Salazar R, Mini E, Folprecht G, Subtil F, Laethem J-L, Thaler J, Bridgewater JA Cutsem EJD, Lepage C, Taieb J: Adjuvant FOLFOX4 plus or minus cetuximab (CMAB) in patients (PTS) with kras mutant (MKRAS) resected stage III colon cancer (CC). Results from the PETACC8 intergroup trial. Ann Oncol 2012, 23(9):ix 178-ix 223.

53. Yashiro M, Qiu H, Hasegawa T, Zhang X, Matsuzaki T, Hirakawa K: An EGFR inhibitor enhances the efficacy of SN38, an active metabolite of irinotecan, in SN38-refractory gastric carcinoma cells. Br J Cancer 2011, 105(10):1522-1532.

54. Braun AH, Stark K, Dirsch O, Hilger RA, Seeber S, Vanhoefer U: The epidermal growth factor receptor tyrosine kinase inhibitor gefitinib sensitizes colon cancer cells to irinotecan. Anticancer Drugs 2005, 16(10):1099-1108

55. Saga Y, Mizukami H, Suzuki M, Kohno T, Urabe M, Ozawa K, Sato I: Overexpression of PTEN increases sensitivity to $\mathrm{SN}-38$, an active metabolite of the topoisomerase I inhibitor irinotecan, in ovarian cancer cells. Clin Cancer Res 2002, 8(5):1248-1252.

56. Moehler M, Mueller A, Trarbach T, Lordick F, Seufferlein T, Kubicka S, Geissler M, Schwarz S, Galle PR, Kanzler S: Cetuximab with irinotecan, folinic acid and 5 -fluorouracil as first-line treatment in advanced gastroesophageal cancer: a prospective multi-center biomarker-oriented phase II study. Ann Oncol 2011, 22(6):1358-1366.

57. de Gramont A, Van Cutsem E, Schmoll HJ, Tabernero J, Clarke S, Moore MJ, Cunningham D, Cartwright TH, Hecht JR, Rivera F, Im SA, Bodoky G, Salazar R, Maindrault-Goebel F, Shacham-Shmueli E, Bajetta E, Makrutzki M, Shang A, Andre T, Hoff PM: Bevacizumab plus oxaliplatin-based chemotherapy as adjuvant treatment for colon cancer (AVANT): a phase 3 randomised controlled trial. Lancet Oncol 2012, 13(12):1225-1233.

58. Allegra CJ, Yothers G, O'Connell MJ, Sharif S, Petrelli NJ, Colangelo LH, Atkins JN, Seay TE, Fehrenbacher L, Goldberg RM, O'Reilly S, Chu L, Azar CA, Lopa S, Wolmark N: Phase III trial assessing bevacizumab in stages II and III carcinoma of the colon: results of NSABP protocol C-08. J Clin Oncol 2011, 29(1):11-16.

59. Chintala S, Toth K, Cao S, Durrani FA, Vaughan MM, Jensen RL, Rustum YM: Se-methylselenocysteine sensitizes hypoxic tumor cells to irinotecan by targeting hypoxia-inducible factor 1alpha. Cancer Chemother Pharmacol 2010, 66(5):899-911.

60. Murono K, Tsuno NH, Kawai K, Sasaki K, Hongo K, Kaneko M, Hiyoshi M, Tada N, Nirei T, Sunami E, Takahashi K, Kitayama J: SN-38 overcomes chemoresistance of colorectal cancer cells induced by hypoxia, through HIF1alpha. Anticancer Res 2012, 32(3):865-872.

61. Guerin E, Raffelsberger W, Pencreach E, Maier A, Neuville A, Schneider A, Bachellier P, Rohr S, Petitprez A, Poch O, Moras D, Oudet P, Larsen AK, Gaub MP, Guenot D: In vivo topoisomerase I inhibition attenuates the expression of hypoxia-inducible factor 1 alpha target genes and decreases tumor angiogenesis. Mol Med 2012, 18:83-94.

doi:10.1186/s13046-014-0083-8

Cite this article as: Thomaidis et al:: Proteins of the VEGFR and EGFR pathway as predictive markers for adjuvant treatment in patients with stage II/III colorectal cancer: results of the FOGT-4 trial. Journal of Experimental \& Clinical Cancer Research 2014 33:83.

\section{Submit your next manuscript to BioMed Central and take full advantage of:}

- Convenient online submission

- Thorough peer review

- No space constraints or color figure charges

- Immediate publication on acceptance

- Inclusion in PubMed, CAS, Scopus and Google Scholar

- Research which is freely available for redistribution 